\title{
Some effects of ultrasound on guinea-pig ear skin
}

\author{
SHIRLEY A. CARNEY, J. C. LAWRENCE, and C. R. RICKETTS \\ M.R.C. Industrial Injuries and Burns Unit, Birmingham Accident Hospital, \\ Bath Row, Birmingham B15 1NA
}

\begin{abstract}
Carney, S. A., Lawrence, J. C., and Ricketts, C. R. (1972). Brit. J. industr. Med., 29, 214-220. Some effects of ultrasound on guinea-pig ear skin. Slices of guinea-pig ear skin were irradiated with ultrasound of frequency $3 \mathrm{MHz}$ for 30 seconds at various power densities. After irradiation the specimens were incubated on a nutrient medium for 24 hours. Measurements of the uptake of ${ }^{32} \mathrm{PO}_{4}{ }^{3-}$ and ${ }^{35} \mathrm{SO}_{4}{ }^{2-}$, skin cell respiration, and dehydrogenase activity were then made. In each case a graded inhibition with increasing power density was observed. These inhibitions were attributed to thermal damage of the skin cells, a view consistent with the histological appearance of the specimens.
\end{abstract}

Ultrasound has long been used in the laboratory for cleaning apparatus and for disrupting bacterial cells and is also finding increased application in industry. Wells (1970) has reviewed the extensive use now made of ultrasonic devices in the medical field. Macintosh and Davey (1970) reported the finding of increased numbers of abnormal chromosomes in human white cells exposed to ultrasound from a fetal pulse detector. It is apparent that greater knowledge of the effects of ultrasound on living tissues is very desirable, and the present study is an attempt to define conditions under which such radiation affects some of the metabolic functions of skin.

\section{Materials and methods}

The apparatus consisted of a continuous wave oscillator at $3 \mathrm{MHz}$ driving a piezoelectric crystal sealed into a water-cooled probe terminated by a thin polythene film. For calibration the probe was placed in the water-bath of an ultrasonic balance, and the sound pressure was balanced by riders of known weight $(67 \mathrm{mg}=1$ watt). The profile of the beam (see Fig. 1) had previously been determined (P. N. T. Wells, private communication) by a thermal method. The central portion only of the beam was used in exposing skin specimens and over this region the mean intensity was $81 \%$ of the maximum intensity as illustrated (Fig. 1). The unit relative intensity was $4 \cdot 88 \mathrm{P}$, where $\mathbf{P}=$ total power in watts. As the specimens were exposed at an average relative intensity of $0 \cdot 81$, the power

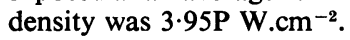

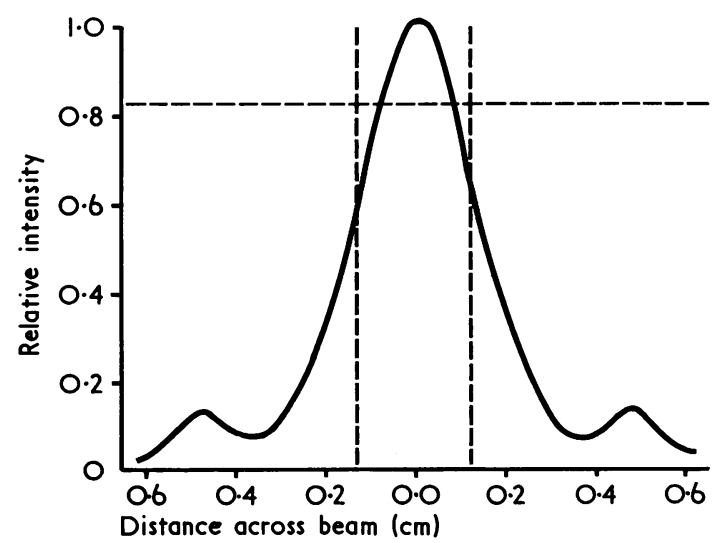

FIG. 1. Energy distribution across the beam emitted!by $3 \mathrm{MHz}$ ultrasonic generator (data of P. N. T. Wells). Vertical lines denote portion of beam occupied by the skin specimen. The mean power density in this region was $81 \%$ of the maximum. 
Skin samples for irradiation were placed inside a polythene ring, $0.25 \mathrm{~cm}$ internal diameter, which was attached to the end of the water jacket surrounding the probe in the path of the centre of the beam, saline being used to ensure contact. The space above the skin was also filled with saline and the whole was covered with a piece of cellophane held in position by surface tension (Fig. 2). This assembly was inverted into a drop of saline on a polythene sheet which covered a water-filled plastic vessel. The sides of this vessel were lined with corrugated rubber to absorb any radiation passing through the specimen (Fig. 3). Specimens were irradiated for 30second periods at power densities from 0 to $33.7 \mathrm{~W} . \mathrm{cm}^{-2}$.

Guinea-pig skin was used in this study, cut from the dorsal surfaces of ears which had been shaved and treated with $2 \%$ iodine in $70 \%$ ethanol on the day before the experiment. Irregular pieces of skin were obtained by freehand cutting with a scalpel and more uniform specimens were obtained from these slices by cutting discs, $0.25 \mathrm{~cm}$ in diameter, with a circular, stainless-steel handpunch. These discs were weighed on a torsion balance,

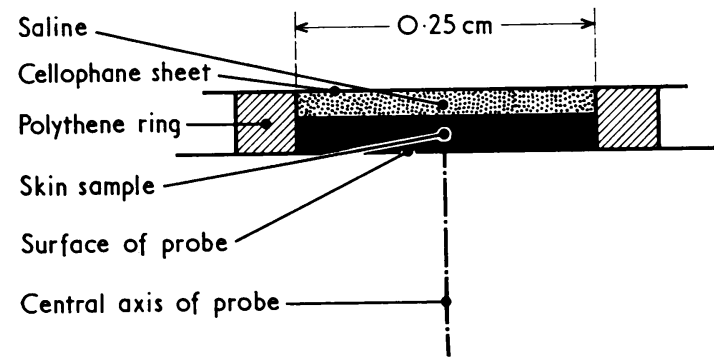

FIG. 2. Arrangement of a skin specimen on the ultrasonic probe.

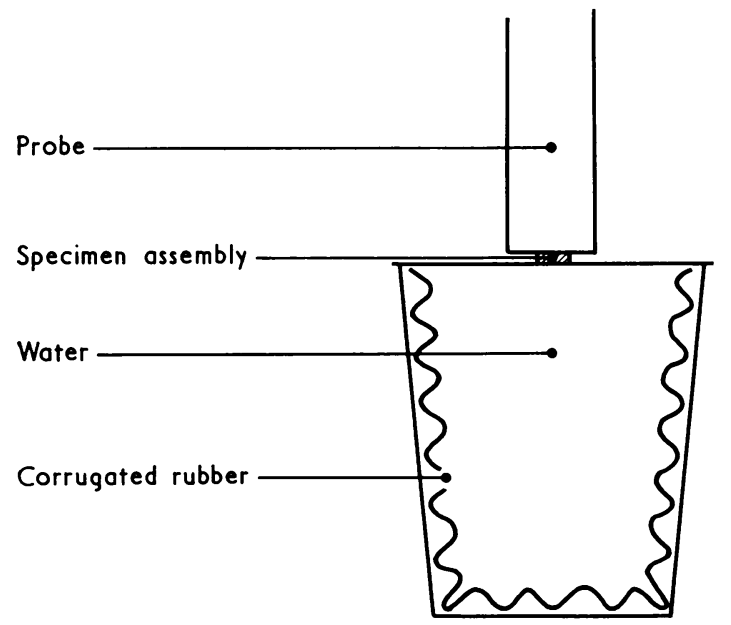

FIG. 3. Arrangement of the ultrasonic probe with skin specimen in position in contact with the absorbing vessel. exposed to ultrasound as described above or retained unirradiated as controls, and maintained for 24 hours at $37^{\circ} \mathrm{C}$ in a nutrient medium. Aseptic precautions were observed throughout the experiment. Other details of the method were as described by Lawrence (1961).

For experiments on uptake of sulphate or phosphate the incubation medium contained $150 \mu \mathrm{Ci}{ }^{35} \mathrm{SO}_{4}{ }^{2-}$ as sodium sulphate (Lawrence and Ricketts, 1957) or $20 \mu \mathrm{Ci} \mathrm{H}^{32} \mathrm{PO}_{4}{ }^{2-}$ as disodium hydrogen phosphate (Carney, Lawrence, and Ricketts, 1962) per $10 \mathrm{ml}$ of medium. Skin samples incubated in the presence of ${ }^{35} \mathrm{SO}_{4}{ }^{2-}$ were killed by freezing, then dialysed free from inorganic sulphate against three changes of $0 \cdot 1 \mathrm{M}$ sodium sulphate during 24 hours at $4{ }^{\circ} \mathrm{C}$. They were then hydrolysed in $6 \mathrm{~N} \mathrm{HCl}$ on a boiling water-bath and the solutions were evaporated to dryness. The residues were dissolved in $1 \mathrm{ml}$ portions of distilled water, and $0.5 \mathrm{ml}$ portions of these solutions were mixed with $10 \mathrm{ml}$ of NE 250 liquid phosphor scintillator (Nuclear Enterprises Ltd.) and counted in a Corumatic 100a (Tracerlab) counter. After correction for volume and background the count rates were expressed per unit fresh weight of skin, and also as a percentage of the value given by the unirradiated skin specimen. Percentage inhibition of isotope uptake was calculated by subtraction from 100 .

Skin incubated in ${ }^{32} \mathrm{PO}_{4}{ }^{3-}$ labelled medium was processed in a similar way except that the dialysis solution was $10 \%(\mathrm{w} / \mathrm{v})$ trichloroacetic acid. The hydrolysed dry residues were dissolved in $0.5 \mathrm{ml}$ portions of distilled water and $0.25 \mathrm{ml}$ portions in $10 \mathrm{ml}$ scintillator were counted. The results were expressed as described above.

Measurements of dehydrogenase activity as described by Hershey, Cruickshank, and Mullins (1958) were made on irradiated skin samples after they had been incubated in serum medium for 24 hours. For this experiment skin discs were irradiated in groups of five at power densities of $0,1 \cdot 7,6 \cdot 0,13 \cdot 9,26 \cdot 3$, and $33 \cdot 7 \mathrm{~W} . \mathrm{cm}^{-2}$.

Skin for histological examination was irradiated at 0 , 13.9, and $33.7 \mathrm{~W} . \mathrm{cm}^{-2}$. Two sets of specimens were prepared, one set being fixed immediately and the other after 24 hours' incubation on serum medium. All specimens for histological examination were fixed in neutral formalin. Standard paraffin sections were prepared and were stained with haematoxylin and eosin.

\section{Results}

As shown in Tables 1 to 4 , the four parameters measured, uptake of ${ }^{35} \mathrm{SO}_{4}{ }^{3-},{ }^{32} \mathrm{PO}_{4}{ }^{3-}, \mathrm{O}_{2}$, and dehydrogenase activity all showed increasing inhibition when the skin had been exposed to increasing power densities of ultrasound. At the two lowest power densities only the values for ${ }^{35} \mathrm{SO}_{4}{ }^{2-}$ uptake were significantly different from control values. The power densities required to produce $50 \%$ inhibition were $11.5 \mathrm{~W} . \mathrm{cm}^{-2}$ for phosphate uptake, 11.0 W. $\mathrm{cm}^{-2}$ for oxygen uptake, $12.5 \mathrm{~W} . \mathrm{cm}^{-2}$ for dehydrogenase activity but only $6.0 \mathrm{~W} . \mathrm{cm}^{-2}$ for sulphate uptake.

Skin discs irradiated at 26.3 W.cm ${ }^{-2}$ and 33.7 W. $\mathrm{cm}^{-2}$ were visibly different from the controls, being thickened and reduced in diameter; a similar effect is seen when skin is heated. 
TABLE 1

Uptake of ${ }^{32} \mathrm{PO}_{4}{ }^{3-}$ By Skin Slices ExPOSEd to Ultrasound: Means \pm S.E.M.(n)

\begin{tabular}{|c|c|c|c|}
\hline $\begin{array}{c}\text { Power } \\
\text { density } \\
\left(W / \mathrm{cm}^{2}\right)\end{array}$ & ${ }^{32} \mathrm{PO}_{4}{ }^{3-}$ uptake (ct/s/mg fresh weight) & $\begin{array}{l}\% \text { inhibition } \\
\text { relative to } \\
\text { control }\end{array}$ & $\begin{array}{c}\text { Statistical comparison } \\
\text { with control }\end{array}$ \\
\hline $\begin{array}{l}0 \\
1 \cdot 7\end{array}$ & $\begin{array}{ll}7184 \pm & 489(5) \\
7422 \pm & 586(5)\end{array}$ & $\overline{-3 \cdot 3}$ & $\overline{\mathrm{NS}}$ \\
\hline $6 \cdot 0$ & $6296 \pm 728(5)$ & $12 \cdot 4$ & $\begin{array}{l}0.7<\mathrm{NS}<0.8 \\
0.3<\mathrm{P}<0.4\end{array}$ \\
\hline 13.9 & $1790 \pm 1090(5)$ & $75 \cdot 1$ & $0.001<\stackrel{S}{P}<0.01$ \\
\hline $26 \cdot 3$ & $1559 \pm 677(5)$ & $78 \cdot 3$ & $P<0.001$ \\
\hline $33 \cdot 7$ & $762 \pm 390(5)$ & $89 \cdot 4$ & $\mathbf{P}<0.001$ \\
\hline
\end{tabular}

NS $=$ not statistically significant

TABLE 2

UptaKe of ${ }^{35} \mathrm{SO}_{4}{ }^{2-}$ by Skin Slices Exposed to Ultrasound

\begin{tabular}{|c|c|c|c|}
\hline $\begin{array}{c}\text { Power } \\
\text { density } \\
\left(W / \mathrm{cm}^{2}\right)\end{array}$ & ${ }^{35} \mathrm{SO}_{4}{ }^{2-}$ uptake (ct/s/mg fresh weight) & $\begin{array}{l}\% \text { inhibition } \\
\text { relative to } \\
\text { control }\end{array}$ & $\begin{array}{c}\text { Statistical comparison } \\
\text { with control }\end{array}$ \\
\hline $\begin{array}{l}0 \\
1 \cdot 7\end{array}$ & $\begin{array}{l}90840 \pm 16253(5) \\
69509 \pm 2893(5)\end{array}$ & $\frac{-}{23 \cdot 5}$ & $\overline{\mathrm{S}}$ \\
\hline $6 \cdot 0$ & $45314 \pm 7531(5)$ & $50 \cdot 1$ & $S$ \\
\hline $13 \cdot 9$ & $21833 \pm 7631(5)$ & $76 \cdot 0$ & $P<0.001$ \\
\hline $26 \cdot 3$ & $1482 \pm \quad 281(5)$ & $98 \cdot 4$ & $P<\frac{S}{0.001}$ \\
\hline $33 \cdot 7$ & $10582 \pm 4424(5)$ & 88.4 & $P<\stackrel{S}{0.001}$ \\
\hline
\end{tabular}

TABLE 3

$\mathrm{O}_{2}$ Uptake of Skin Slices Exposed to Ultrasound

\begin{tabular}{c|c|c|c}
\hline $\begin{array}{c}\text { Power } \\
\text { density } \\
\left(\mathrm{W} / \mathrm{cm}^{2}\right)\end{array}$ & $\mathrm{O}_{2}$ uptake $(\mu \mathrm{l} / \mathrm{mg} \mathrm{h})$ & $\begin{array}{c}\% \text { inhibition } \\
\text { relative to } \\
\text { control }\end{array}$ & $\begin{array}{c}\text { Statistical comparison } \\
\text { with control }\end{array}$ \\
\hline 0 & $109.7 \pm 12.0(3)$ &.- & - \\
1.7 & $98.5 \pm 12.0(3)$ & 10.2 & $\mathrm{NS}$ \\
13.9 & $26.3 \pm 0.72(3)$ & 66.0 & $0.5 \quad \mathrm{P}<0.6$ \\
33.7 & $1.3 \pm 0.60(3)$ & 98.8 & $0.001<\mathrm{P}<0.01$ \\
\hline
\end{tabular}


TABLE 4

Reduction of 2,3,5-Triphenyltetrazolium Chloride by Skin Slices Exposed to Ultrasound

\begin{tabular}{|c|c|c|c|}
\hline $\begin{array}{l}\text { Power } \\
\text { density } \\
\left(W / \mathrm{cm}^{2}\right)\end{array}$ & T.T.C. reduction $(E 570 / \mathrm{mg})$ & $\begin{array}{c}\% \text { inhibition } \\
\text { relative to } \\
\text { control }\end{array}$ & $\begin{array}{l}\text { Statistical comparison } \\
\text { with control }\end{array}$ \\
\hline 0 & $0.191 \pm 0.035(5)$ & - & \multirow{6}{*}{ 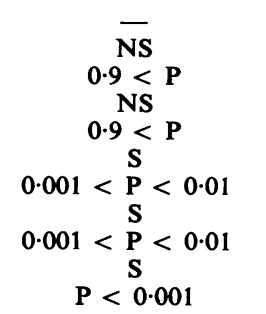 } \\
\hline $1 \cdot 7$ & $0.189 \pm 0.042(5)$ & $1 \cdot 0$ & \\
\hline $6 \cdot 0$ & $0.148 \pm 0.035$ & $22 \cdot 5$ & \\
\hline $13 \cdot 9$ & $0.041 \pm 0.014$ & $64 \cdot 4$ & \\
\hline $26 \cdot 3$ & $0.017 \pm 0.006(5)$ & $91 \cdot 1$ & \\
\hline $33 \cdot 7$ & $0.014 \pm 0.003(5)$ & $92 \cdot 7$ & \\
\hline
\end{tabular}

Skin sections examined immediately after exposure to ultrasound showed no striking histological changes compared to control skin. Figure 4A shows control (i.e., unirradiated) skin; Fig. 4B is a section prepared from skin exposed for 30 seconds to $33 \cdot 7$ W. $\mathrm{cm}^{-2}$. There was no alteration to the structure of the tissue and no particular evidence of cavitation. The keratin layer seemed to be more firmly attached to the remainder of the tissue; in unexposed skin it tends to separate.

The appearance of skin incubated for 24 hours following irradiation was different from the controls. Unirradiated specimens exhibited a normal histology for incubated skin (Fig. 5A) but skin exposed for 30 seconds to $33 \cdot 7 \mathrm{~W} . \mathrm{cm}^{-2}$ stained abnormally and necrosis was more advanced (Fig. 5B). Skin which has been heated to 55 to $60^{\circ} \mathrm{C}$ for about 30 seconds and then incubated for 24 hours shows a similar histology.

\section{Discussion}

The inhibition of the biochemical activities of skin resulting from irradiation with ultrasound is similar to that seen in previous work on the effects of heat on skin (Lawrence and Ricketts, 1957; Carney et al., 1962). It has been suggested that it represents the distribution of susceptibilities of a population of cells to the damaging agent. Possibly this variation is one of age, comparable with the age variation which can be demonstrated in a population of red cells (Baar and Arrowsmith, 1970), the young cells being those which are easily inhibited and the oldest cells being the most resistant to damage. The greater sensitivity to damage by ultrasound of the processes involved in sulphate uptake is of particular interest and may be a more specific effect. It is possible that ultrasound of this frequency can specifically destroy enzymes involved in the synthesis of high molecular weight sulphate compounds. Alternatively, the inhibition of sulphate uptake might have resulted from the action of a toxin liberated by heat damage. Jones and Lawrence (1964) showed that an extract from heat-damaged skin could inhibit sulphate uptake by skin slices. In support of this latter view, Wells (1968) has shown that there is a threshold level of ultrasonic intensity below which biological damage is thermal in origin, mechanical effects contributing only at the higher levels.

As expected, the inhibition of dehydrogenase activity in the skin samples, as measured by the reduction of 2,3,5-triphenyltetrazolium chloride, closely paralleled the results of the respiration studies. It is interesting to note that the power density required to produce $30 \%$ inhibition was about $7.4 \mathrm{~W} . \mathrm{cm}^{-2}$ in each case. Lawrence (1969) demonstrated that a $30 \%$ loss of oxygen uptake by skin represents a threshold above which histological abnormalities occur when the explant is maintained in tissue culture.

There was no histological evidence suggesting that ultrasound had any specific effect on skin. Cavitation might be expected, particularly at high dose levels but there was no convincing evidence that cavitation had occurred.

However, ultrasound is known to cause cavitation in tissues (Wells, 1970). It is reasonable to suppose that any ultrasound energy absorbed by skin is converted to heat and that this heat is responsible for the subsequent metabolic and histological changes in the tissue. The possible increase in adherence of the keratin could well be a thermal effect (mild coagulation of the tissue). The subsequent necrosis of skin incubated after exposure also occurs after mild thermal damage (Cruickshank, 1954) and after exposure to various types of electromagnetic radiation. In the case of skin exposed to laser light and microwaves the ensuing damage was 


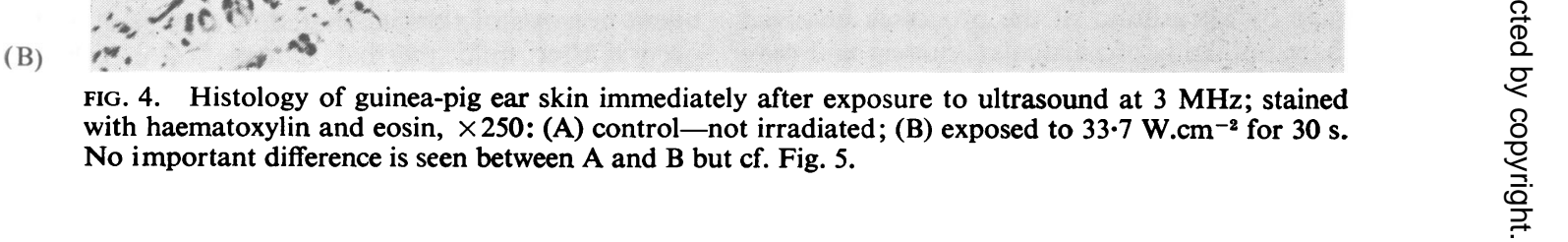



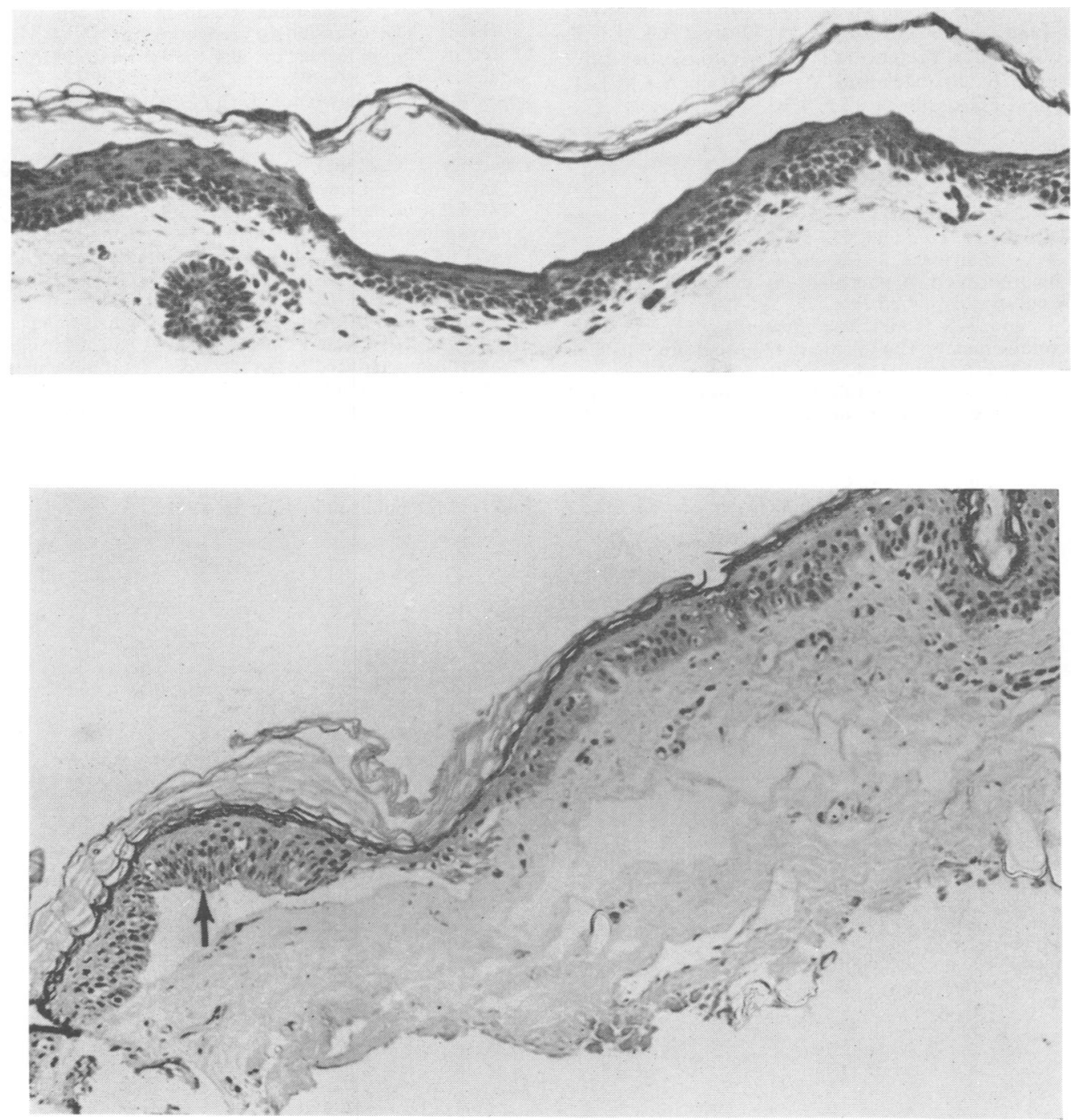

FIG. 5. Histology of guinea-pig ear skin incubated on a nutrient medium for $24 \mathrm{~h}$ following exposure to ultrasound; stained with haematoxylin and eosin, $\times 250$ : (A) control-not irradiated; (B) exposed to 33.7 W.cm-2 for $30 \mathrm{~s}$. (A) Normal histological appearance of incubated skin. (B) Signs of necrosis may be seen in skin incubated after exposure to ultrasound.

thought to be due to heat (Carney, Lawrence, and Ricketts, 1967; 1968).

The power level causing $50 \%$ inhibition was 11.0 W.cm ${ }^{-2}$ for respiration and 12.5 W.cm ${ }^{-2}$ for dehydrogenase activity, applied for 30 seconds in each case. The total energy was thus about $336 \mathrm{~J}$ or 80 calories. The weight of $1 \mathrm{~cm}^{2}$ of the split-thickness skin used would be about $15 \mathrm{mg}$. If the energy was absorbed and completely converted to heat by the skin the rise in temperature could theoretically be more than $100^{\circ} \mathrm{C}$. Thus it seems likely that only a small fraction of the total energy is absorbed and that the rise in temperature is small, consistent with the biochemical and histological changes observed. The skin was in good thermal contact with a large mass of water at room temperature and the probe itself was adequately cooled. In these experimental circumstances it seems likely that there was remarkably little effect of ultrasound per se and that our observations are consistent with mild thermal damage. 
The authors thank Dr. P. N. T. Wells for valuable advice and the loan of equipment; Mr. R. Dyster, A.I.M.L.T. for the histological preparations and photomicrography; and Mrs. E. K. Brookes and Mr. M. Hall, A.I.M.L.T. for technical assistance.

\section{References}

Baar, S., and Arrowsmith, D. J. (1970). Thermal damage to red cells. J. clin. Path., 23, 572-576.

Carney, S. A., Lawrence, J. C., and Ricketts, C. R. (1962). The incorporation of phosphate by mammalian skin in tissue culture. Exp. Cell Res., 27, 587-591.

,-- , and - (1967). The effect of light from a ruby laser on the metabolism of skin in tissue culture. Biochim. biophys. Acta (Amst.), 148, 525-530.

,-- and - (1968). Effect of microwaves at X-band on guinea-pig skin in tissue culture. 2. Effect of the radiation on skin biochemistry. Brit. J. industr. Med., 25, 229-234.

Cruickshank, C. N. D. (1954). Continuous observation of the respiration of skin in vitro. Exp. Cell Res., 7, 374-380.
Hershey, F. B., Cruickshank, C. N. D., and Mullins, L. I. (1958). The quantitative reduction of 2,3,5-triphenyl tetrazolium chloride by skin in vitro. J. Histochem. Cytochem., 6, 191-196.

Jones, R. J., and Lawrence, J. C. (1964). Studies on extracts of heated and normal skin. Brit. J. exp. Path., 45, 198206.

Lawrence, J. C. (1961). Factors influencing skin metabolism as shown by tissue culture. In Wound Healing, Proceedings of a Symposium, 1959, edited by D. Slome, pp. 32-45. Pergamon Press, Oxford.

(1969). Effect of ruby laser on white guinea-pig skin in tissue culture. Non-Ionizing Radiation, 1, 18-22.

- and Ricketts, C. R. (1957). The metabolic uptake of sulphate ions by skin. Exp. Cell Res., 12, 633-638.

Macintosh, I. J. C., and Davey, D. A. (1970). Chromosome aberrations induced by an ultrasonic fetal pulse detector. Brit. med. J., 4, 92-93.

Wells, P. N. T. (1968). The effect of ultrasonic irradiation on the survival of Daphnia magna. J. exp. Biol., 49, 61-70.

(1970). The medical applications of ultrasonics. Rep. Progr. Phys., 33, 45-99.

Received for publication June 30, 1971 